


\title{
Política afirmativa racial: polêmicas e processos de identidade do cotista universitário ${ }^{1}$
}

\author{
Maria da Penha Nery² - Universidade de Brasilia, Brasilia, Brasil \\ Liana Fortunato Costa - Universidade de Brasilia, Brasilia, Brasil
}

\begin{abstract}
Resumo
Trata-se de um estudo de caso cujo objetivo foi investigar a afetividade intergrupal com base na implantação de política afirmativa para o ingresso de negros nas universidades públicas. O enfoque teórico foi o da Socionomia e o contexto foi a Universidade de Brasília. Os sujeitos foram 5 estudantes e 5 integrantes de uma ong. Os instrumentos foram um sociodrama e entrevistas semi-estruturadas. A autocobrança para excelente desempenho acadêmico, por parte dos cotistas e do estudante negro, foi uma das atitudes mais presentes, na busca de saída para a discriminação vivida ou sentida no processo inclusivo. A dinâmica afetiva dos estudantes universalistas foi a indiferença e o descaso ou desqualificação em relação às causas raciais. Concluímos que um projeto de inclusão racial efetiva depende de uma intervenção psicossocial multidisciplinar voltada para as redes sociométricas visando à flexibilização da identidade, o diálogo empático, a solidariedade entre os estudantes.

Palavras-chave: afetividade; participação política; universidade; sociometria.
\end{abstract}

\section{Affirmative action: polemics and identity processes of the university student}

\begin{abstract}
This text refers to a case study that analyzed the intergrupal affectivity in the implementation of the afro descendents admission affirmative polictic at public universities. Socionomy was used as the theoretical focus of the study and it was carried out in the University of Brasília context. The participants were 5 students and 5 members of an NGO. The instruments used were the Sociodrama and semi-structured interviews. Self-demanding for an excellent academic performance was the most noticeable attitude of the quota students and afro descendents in their search for a way out of the discrimination situation lived or perceived in the inclusive process. In regard to the affective dynamics, the university students showed unresponsiveness and unconcerned attitudes towards racial causes. We concluded that an effective racial inclusive project depends on a multidisciplinary psychosocial intervention directed to the sociometric nets, aiming at identity flexibility, empathic dialogue and solidarity building among the students.

Keywords: affection; political participation; university; sociometry.
\end{abstract}

\section{Introdução}

Este texto trata, de forma resumida, de uma pesquisa qualitativa cujo objeto de estudo foi a afetividade intergrupal estabelecida a partir da implantação de política afirmativa para o ingresso de negros nas universidades públicas. Este tema é mais conhecido como a política de implantação de cotas para negros nas universidades.

Considerando o projeto original, esta pesquisa teve como objetivos: a) observar as interações afetivas dos sujeitos universitários envolvidos num processo de inclusão sociorracial; b) conhecer as significações nas interações dos sujeitos aprovados e dos que não fazem parte do sistema dessa ação afirmativa; c) compreender as implicações dos sentimentos, dos significados e dos processos identitários encontrados na sociodinâmica desses sujeitos; e d) analisar as influências das interações afetivas num processo de inclusão sociorracial. Neste texto resumido, apontamos como objetivos aqueles que dizem respeito à afetividade intergrupal e aos processos identitários. Para melhor situar os sujeitos envolvidos, indicamos que cotista é o papel desempenhado pelo indivíduo que é aprovado no vestibular para a universidade por meio de sistema de cotas raciais; e universalista é o papel desempenhado pelo indivíduo que faz o vestibular optando pelo sistema universal. Partimos de uma hipótese de que o processo de inclusão sociorracial efetivamente ocorre quando os sujeitos que dele participam direta e indiretamente reorganizam projetos dramáticos, com o objetivo de produzir status sociométricos que favoreçam a integração social dos sujeitos aprovados pelo sistema de cotas no vestibular para o ingresso de negros na universidade. Consideramos que a explicitação da afetividade resultante da experiência da política inclusiva pode produzir novas percepções de si e do outro (percepções identitárias), mobilizar a consciência política, elucidar as significações nas interações e motivar ações que efetivem a inclusão racial. Portanto, apresentamos um estudo de caso da Universidade de Brasília (UnB), que foi realizado

\footnotetext{
${ }^{1}$ Este texto está baseado na Tese de Doutorado "Afetividade intergrupal, política afirmativa e sistema de cotas para negros", realizada pela primeira autora, orientada pela segunda, e defendida perante o Programa de Pós-Graduação em Psicologia Clínica e Cultura em março de 2008.

${ }^{2}$ Endereço para correspondência:
}

SQSW 102 - Bloco C - Ap. 502 - 70.670-203 - Sudoeste - Brasília-DF, Brasil

Tel-fax: (61) 33-442029

E-mail: mpnery@yahoo.com.br 
numa perspectiva teórica da Socionomia, a ciência dos grupos de Moreno (1974), e os instrumentos de coleta de informações foram o Sociodrama e entrevistas semi-estruturadas.

\section{Politicas afirmativas e seus pressupostos filosóficos}

Os pressupostos filosóficos e sociológicos das políticas afirmativas caminham desde visões otimistas de suas eficácias para a transformação da sociedade até visões críticas do sistema neoliberal, que afirmam que essas políticas diminuem a tensão das lutas de classe e $\mathrm{o}$ alcance de seus objetivos de mudanças estruturais na sociedade. Segundo Andrews (1997) e Gomes (2001), as bases filosóficas das políticas afirmativas são a justiça distributiva e a justiça compensatória. A política afirmativa é um conjunto de medidas públicas ou privadas concebidas para um público-alvo que sofreu e sofre discriminações geradoras, inclusive, de bloqueio aos bens sociais, culturais e materiais. Busca-se o combate à discriminação, por meio, por exemplo, de aumento da oportunidade de acesso aos bens da sociedade (Gomes, 2001).

Kerstenetzky (2005) aponta três sentidos para as políticas sociais de focalização, como é o caso das políticas afirmativas: para a justiça de mercado, essas políticas são residuais ou um seguro social para os segmentos que ficam à margem dos processos econômicos integradores, protegendo a pobreza imerecida, resultante das incertezas do mercado; os tecnólogos sociais veem na focalização a condicionalidade para que se tenha um foco que seja adequadamente atendido e para que se atinja a solução de um problema previamente estudado em suas variáveis econômica, social, geográfica etc. Por fim, há o sentido de focalização como ação reparatória, que possibilite a grupos sociais específicos, que vivem a desigualdade de oportunidades de realização socioeconômica, o acesso efetivo a direitos universais formalmente iguais. A justiça distributiva admite os sentidos de focalização como condicionalidade e como retificação ou redistribuição, além de conjugá-la com a universalização para a sua eficiência social. Porém, tanto a noção de justiça distributiva quanto a de justiça compensatória são revistas por Demo (2003b), pois não resultam de fato na "redistribuição equânime" da riqueza, mas no impedimento da justiça redistributiva e de políticas que efetivamente promovam a emancipação e a dignidade aos cidadãos. Segundo Demo (2003b), tanto um método quanto o outro podem servir à manutenção do sistema, pois em vez de emancipar o pobre, podem ativar o efeito de poder. O efeito de poder é o resultado de políticas públicas e sociais que, ao contrário de seus objetivos de emancipação do pobre, confirmam-no na miséria, estigmatizando-o ainda mais e reproduzindo a desigualdade social (Popkewitz, 2001).

\section{A polêmica do sistema de cotas para negros}

Uma das políticas afirmativas que têm gerado grande polêmica no país é o sistema de cotas raciais, em que se reservam vagas para negros ingressarem nas universidades. No debate acadêmico há, basicamente, as tendências de pensamento favoráveis e as desfavoráveis em relação às cotas para negros. Fazem parte da tendência pró sistema de cotas raciais vários intelectuais, dentre eles: Carone e Bento (2002), Carvalho e Segato (2002), Gomes (2001), Guimarães (1999, 2002), Munanga (1996, 1999), Queiroz (2004), Santos (2007) e Santos e Lobato (2003). E a tendência contrária às cotas raciais é liderada, entre tantos intelectuais, por Azevedo (2004), Da Matta (1997), Fry (2005), Maggie (2001), Maio e Santos (2005) e Reis (1997). Quanto à corrente dos favoráveis às cotas para negros, cada autor, a sua maneira, argumenta a imprescindibilidade da política para a diminuição do racismo e da desigualdade racial no país. Essa tendência, em distintos níveis, acompanha as reivindicações do movimento negro, relacionadas ao desenvolvimento da identidade e da consciência negras e ao desmascaramento das ideologias relativas às relações raciais no Brasil.

Segundo Guimarães (1999), a partir da década de 1940, o racismo brasileiro foi silenciado com a disseminação da ideologia freyreana da democracia racial e do país miscigenado. Porém, a miscigenação resultou na desidentidade social e cultural do negro e do índio (Munanga, 1999). A indiferença política, a exaltação à cultura européia, a política de embranquecimento da população, o incentivo à imigração européia promoveram a exclusão do trabalhador negro, no início do séc. XX, embrião do processo industrial brasileiro (Carone \& Bento, 2002). Dentro desse processo sociohistórico, a trajetória social do negro segue fluxo sem que a cor seja responsabilizada. Bastide e Fernandes (1955) se referem a tal trajetória comportamental como embranquecimento, que distancia o negro de sua cultura e valores. O novo negro é aquele que tem consciência de sua identidade e da discriminação que sofre. Com o objetivo de manter a ideologia do paraíso racial, o Estado e a sociedade também exacerbam a influência das classes sociais, como o mote do problema socioeconômico, e simplificam as contradições grupais e intergrupais. No entanto, segundo Guimarães (1999, 2002) e Elias e Scotson (1994), esse conceito deve ser ampliado, pois é preciso pesquisar todas as formas de coerção nãoeconômicas que compõem a sociabilidade capitalista, dentre elas: gênero, idade, etnia, raça, religião, nacionalidade ou outra forma de construção de outsiders. 
O retorno do processo democrático na década de 1980, o fortalecimento do movimento negro, a Constituição de 1988, a participação do Brasil na III Conferência de Durban, em 2001, em que o país admitiu mundialmente seu racismo, e a criação de organizações não-governamentais (ONGs) que lutam pela causa negra foram grandes acontecimentos que promoveram uma virada nas relações raciais no país. Carvalho e Segato (2002), Guimarães (1999, 2002), Munanga (1999) e Santos (2002) reafirmam a noção analítica de raça, na concepção de uma construção social. Guimarães (2002) assevera: raça não é apenas uma categoria política necessária para realizar a resistência ao racismo, mas é também uma categoria analítica que revela que as discriminações e desigualdades são efetivamente raciais e não referentes apenas à classe social. Para Gomes (2001), as ações afirmativas têm um cunho pedagógico, pois politizam e mobilizam a sociedade civil, na medida em que os cidadãos, por meio delas, se veem como interventores sociais, e caracterizam o Estado como promovente e atuante, pois intervém em todas as suas instâncias para concebê-las e implantá-las.

Assim, uma crise social emerge da força dos movimentos negro e indígena e das convenções internacionais, evidenciando-se o direito de serem iguais, sem que a diferença os inferiorize, e o direito de serem diferentes, sem que a igualdade os descaracterize. Para Santos (2006), projetos de lei como o das cotas e do Estatuto da Igualdade Racial têm alto valor democrático e mostram que o reconhecimento do racismo só é legítimo quando efetivamente se busca eliminá-lo. $\mathrm{Na}$ corrente opositora às cotas raciais, os intelectuais argumentam, de maneiras específicas, que as políticas raciais afirmativas, particularmente $\mathrm{O}$ sistema de cotas, são reinstauradoras das crenças em raças, justamente o fundamento do racismo. Os aracialistas acreditam que o Brasil possui democracia e convivência pacífica racial. Segundo Fry (2005), quando o movimento negro apregoa princípios segregacionistas não se identifica e não se comunica com a massa que se vê dentro da democracia racial. Fry (2005) e Monteiro (2003) temem que as universidades, ao optarem pelas cotas raciais, favoreçam os privilegiados prejudiquem os brancos pobres. Para Demo (2003b), o sistema de cotas tem o critério vexatório de certificar o negro. $\mathrm{O}$ mais adequado seria, segundo esse autor, o critério da origem da escola pública, pois daria oportunidade de inserção expressiva de alunos pobres e o negro estaria inserido além das cotas fixadas para ele. Há, ainda, o risco do efeito de poder dessa política, principalmente se não houver a concepção e o controle dessas políticas por parte dos interessados (Demo, 2003a;
2007). A universidade já é "cota” da elite, que tentará tudo para manter seus privilégios e rebaixar a oportunidade dos negros (Demo, 2007).

\section{Nossa opção teórica}

O referencial teórico da pesquisa foi a socionomia de Moreno (1972, 1974), para quem os processos grupais podem ser desvelados por intermédio da sociodinâmica, que estuda os papéis e as funções dos indivíduos nos grupos, e da sociometria, que estuda as estruturas grupais e as posições dos indivíduos nas interações grupais, ocasionadas pela distribuição da afetividade. Para Moreno (1974) o grupo é um microcosmo que representa (ou reflete) o macrocosmo da sociedade, pois o entrelaçamento dos conteúdos coinconscientes produz uma interferência e um aprendizado mútuo entre ambas as instâncias. As forças de atração e repulsão compelem as pessoas a se juntarem ou se afastarem, mediante múltiplos e complexos critérios sociométricos socioculturais, dentre eles: vizinhança, amizade, categorias profissionais, ideologias e valores. Nesse sentido, os grupos impõem identidade aos papéis dos indivíduos. No entanto, eles, por meio da liberação da espontaneidade-criatividade, conseguem fluir na existência, num constante processo de vir-a-ser. A análise socionômica dos processos grupais, subjetivos e intersubjetivos, se dá por meio da tricotomia social. A tricotomia social é o engendramento de realidades distintas e interdependentes que compõem o campo sociométrico. Estas realidades são: realidade social, realidade externa e matriz sociométrica. A realidade externa é a realidade formal dos papéis sociais (por exemplo: grupo dos sem-terra, grupo dos deputados e outros). A matriz sociométrica é a realidade informal em suas estruturas e fluências ocultas e afetivas: afinidades, identificações, escolhas para realizações de projetos dramáticos primários e secundários, jogos de poder que fracionam os grupos (por exemplo: subgrupos dos que apoiam invasões; subgrupos dos que querem negociar; redes de intrigas; papéis latentes daquele que boicota, do poderoso, do fofoqueiro). $\mathrm{Na}$ realidade social está o inconsciente comum grupal (o co-inconsciente), gerador das dinâmicas e das padronizações vinculares (por exemplo: grupo combativo, apático, dissimulado). A realidade social é a resultante dos intercâmbios entre a realidade externa e a matriz sociométrica.

\section{Método}

Consideramos este estudo como estudo de caso, em sua abrangência, por buscar conhecer o 
sujeito na situação concreta, na sua experiência, na sua vida, tentando retratar, o máximo possível, o dinamismo da situação em seu acontecer natural (Stake, 1995). Porém, também situamos este estudo dentro do quadro da pesquisa-ação na perspectiva de que a situação de coleta de informações gerou, por sua natureza expressiva, possibilidades de reflexões e transformações nas interações ocorridas durante $\mathrm{o}$ processo (Barbier, 2002). Podemos agregar comentários de autores tais como Marra e Costa (2004), que concluem que o sociodrama é um método que se coaduna com a pesquisa-ação. Segundo as autoras, a pesquisa-ação se fundamenta, tal qual a socionomia, epistemologicamente nos grupos, nas comunidades e na dimensão relacional. No sociodrama, os sujeitos encontram personagens latentes espontâneos-criativos que dinamizam os estados coconcientes e coinconscientes (Moreno, 1983). Esses estados fornecem ao grupo as dinâmicas e características que lhe são peculiares.

O acesso ao campo deu-se por meio de: a) entrevistas com implantadores do sistema de cotas na UnB, para que as pesquisadoras (responsáveis pelo projeto) pudessem compreender o contexto e o clima de implantação do sistema; e b) a realização de seis sociodramas - pilotos (do $1^{\circ}$ semestre de 2003 até o $2^{\circ}$ de 2006) como treinamento para a formação da equipe de pesquisa (pesquisadoras responsáveis e auxiliares de pesquisa) e a percepção de dificuldades na organização de tal método.

Os sujeitos foram: a) 5 estudantes (um negro universalista, e quatro estudantes não cotistas), com idades entre 20 e 23 anos; sendo 4 do sexo masculino e um do sexo feminino, e renda familiar média de 6 000 reais. Todos os estudantes, quatro de cor branca e um de cor negra, entraram na universidade através do sistema universal de vestibular, num período compreendido entre o primeiro e o terceiro vestibular após a implantação do sistema de cotas. Nenhum estudante que entrou pelo sistema de cotas quis fazer parte do projeto. Em virtude desse detalhe, as pesquisadoras decidiram entrevistar três estudantes cotistas e um membro de uma ONG, que se propõe a prestar apoio aos estudantes do sistema de cotas. Essa ONG atua dentro da universidade. Os sujeitos foram: 3 estudantes do sexo feminino e um funcionário da ong, todos negros, com idades entre 21 e 28 anos, que não quiseram declarar renda familiar. As três estudantes são cotistas e entraram pelo sistema de cotas entre o segundo e o quarto vestibular desde a implantação do sistema. O funcionário tem pós-graduação.

O instrumento foi o sociodrama, que é um método de pesquisa qualitativa com a característica da intervenção socioterapêutica, fundamenta-se na epistemologia socionômica e busca superar as dicotomias da pesquisa quantitativa/qualitativa e a de indivíduo/coletividade, ao privilegiar o estudo do(s) sujeito(s) em suas relações e na situação. O método sociodramático visa ao tratamento de síndromes culturais coletivas e à cocriação, que é a complementação de papéis sociais que proporciona o bem-estar grupal (Aguiar, 1998; Nery, 2003; Perazzo, 1994) e está proposto como método de pesquisa qualitativa por Nery, Costa e Conceição, 2006. A pesquisa contou ainda com a obtenção de outras informações por meio de entrevista semi-estuturada. O sociodrama foi a opção para se obter as informações advindas dos estudantes e a entrevista foi a opção relativa aos participantes da ONG. O sociodrama foi registrado em vídeo, e as entrevistas foram gravadas em áudio.

A análise das informações foi realizada em dois momentos: primeiro houve um ordenamento $\mathrm{e}$ classificação. Segundo Minayo (2006) a ordenação dos dados engloba as transcrições de fitas e vídeos, releitura do material, organização dos relatos, documentos e observações dos dados em classificação prévia, de acordo com a proposta analítica. É um processo de interação intensa com as informações obtidas na pesquisa. O material empírico sobre o tema é visto em conjunto, como um corpus a ser analisado tecnicamente. Assistimos exaustivamente ao vídeo e ouvimos diversas vezes as entrevistas. Fizemos, conforme proposta da autora, anotações de nossas impressões, na busca da coerência interna das informações. Em segundo lugar, procedemos à análise de conteúdo proposta por González Rey (2005), centrada nos indicadores para a construção de zonas de sentido (principalmente das interações afetivas $\mathrm{e}$ atitudinais entre esses estudantes). A cena mais escolhida pelos grupos, durante o período dos sociodramas pilotos e no sociodrama para esta pesquisa foi o resultado do vestibular em que se implantou o sistema de cotas, de onde emergiram conflitos entre os que passaram por cotas e os que não conseguiram passar por causa da implantação do sistema. Esses conflitos dizem respeito a disputas e concepções de merecimento pela entrada na universidade.

\section{Discussão dos Resultados}

A dinâmica afetiva grupal é a emocionalidade que compõe as crenças, atitudes e comportamentos do grupo (e de seus subgrupos) na experiência da competição social. Essa dinâmica fundamenta os projetos dramáticos (critérios de escolhas para 
determinadas ações e tarefas) e dinamiza a sociometria do grupo (Nery, 2003). A sociometria, segundo Moreno (1972) estuda a distribuição de afetos entre os indivíduos no grupo, demonstrando sua posição afetiva. Quanto à dinâmica afetiva grupal, a autocobrança para excelente desempenho acadêmico, por parte dos cotistas e do estudante negro, foi uma das atitudes mais presentes na busca de saída para a discriminação vivida ou sentida no processo inclusivo. Por exemplo, nessa entrevista, a estudante nos diz:

Entrevistada cotista: Aqui dentro da universidade, um dos sofrimentos do cotista é que você tem que provar que você pode, sabe? Que você pode... Que você está aqui e conseguiu a vaga por mérito seu, sabe? ...tem esta história da nota de corte menor... você tem que ficar provando que você é bom, que você pode, que você pode estudar tanto quanto o universalista, sabe?

A dinâmica afetiva dos estudantes universalistas, predominante em nosso estudo, foi a indiferença e o descaso ou desqualificação em relação às causas raciais. $O$ cotista é visto como um beneficiado e privilegiado pela política afirmativa; é julgado como uma nota de corte inferior, ele e o estudante negro são considerados incapazes, depreciados em seu mérito, não merecedores de estarem na universidade. Vejamos este trecho do debate inicial do Sociodrama:

Estudante universalista 1: Não quero entrar no mérito da questão racial. O cotista ser visto como um beneficiado, não acho que é racismo! Por exemplo, a mesma coisa fariam com pessoal de colégio público...

Estudante universalista 2: Mas... Fica uma classe branca nas classes média, alta e rica, predominantemente e os negros ficam predominantemente na classe pobre. Isso está errado, tem que ser alterado!

Estudante universalista 1: Sim, isso está errado. Mas não é isso que a gente tá falando aqui!

Estudante universalista 2: Também isso! Não falei da sua atitude, mas de toda uma mentalidade que se esconde por trás desse seu pensamento, e é uma mentalidade racista.

Estudante Universalista 1: Ab! Pô, obrigado, eu não sabia. Tive um excelente insight agora! Tá certo, então!

$\mathrm{Na}$ dramatização, a cena escolhida foi a do resultado do vestibular, em que houve interação entre os participantes nos personagens: candidata universalista que foi reprovada, cotista, universalista, negro universalista e branca cotista. A dinâmica afetiva intergrupal prevalecente é a relacionada à desconfiança da capacidade do cotista e ao sentimento de injustiça relacionado ao sistema de cotas; à raiva da discriminação e ao sentimento de culpa por ocupar vaga do outro. Essa dinâmica nos traz uma sociometria em que não há integração grupal ou um isolamento do negro em relação ao grupo. No fracionamento grupal predominou a desqualificação das questões raciais e raiva disso derivada (hostilidade intergrupal) $\mathrm{x}$ minimização dos conflitos raciais (desejo de união). Essas dinâmicas afetivas geram, pois, uma discriminação específica na experiência do sistema de cotas, sustentada por um mecanismo afetivo de poder que denominamos de "antiempatia". Antiempatia é a indisponibilidade em se imaginar no lugar do outro e sentir seus sentimentos e razões, particularmente do universalista em relação ao negro e ao cotista. Esse mecanismo tem uma função eficiente de reproduzir o racismo e de manter o status quo social.

A afetividade intergrupal promove interferências específicas nos processos identitários, ou seja, no desenvolvimento da identidade dos papéis de cotista e de universalista, neste histórico contexto inclusivo. Para Moreno (1974), os papéis sociais carregam os elementos coletivos que se tornam a identidade do papel e os elementos individuais que possibilitarão o processo secundário de identificação do papel. Tanto a operação psicossocial de identidade total, como a operação da diferenciação são vividas a cada encontro grupal. Nesse sentido, o autor afirma:

A identidade deveria ser considerada à parte do processo de identificação. Desenvolve-se antes deste último na criança pequena e atua em todas as relações intergrupais da sociedade adulta. Para a criança pequena, "eu" e "meio imediato" são a mesma coisa; não existe, para ela, uma relação eu-outro. [...] No nível adulto, para os não-negros, por exemplo, todos os negros são considerados idênticos: o negro. [...] Os negros consideram-se a si mesmos um coletivo singular: o negro, uma condição que submerge todas as diferenças individuais (Moreno, 1974, p. 442)

A identidade é, pois, um coletivo simbólico que tem poder sobre a imaginação humana. O indivíduo e o grupo ao qual pertencem vivem a contradição de terem características permanentes (que lhe dão uma identidade) e a capacidade de transforma-se constantemente (num fluente vir-a-ser espontâneo e criativo).

$\mathrm{Na}$ pesquisa, encontramos os seguintes processos de identidade: o paradoxo identitário, e as experiências da identidade radical, da identidade oculta e da identidade flexível. O paradoxo identitário é um mecanismo social, vivido por indivíduos e grupos discriminados, que congrega tanto o desejo de 
expor a identidade quanto o temor em expô-la, ocasionando perturbações em seu processo político de organização social. Esse mecanismo também se compõe das ambivalências na vivência das identidades sociais. Por exemplo, há cotistas que assumem a identidade racial para o ingresso na universidade, porém não a assumem no contexto acadêmico, pelo temor da discriminação.

Entrevistada cotista: Têm pessoas que entram, têm consciência, sabe? mas têm aquele medo e aquele receio de se abrir e ser discriminado, porque nem todo mundo está preparado para isso. Nem todo mundo quer ou tem uma consciência de poder discutir isso com alguém. Então... mesmo que se reconbeceram como negro, preferem se manter à margem e não entrar em discussão.

O paradoxo identitário é a experiência de assumir e de ao mesmo tempo não assumir o novo papel social, em nosso caso, de cotista ou de universalista. Esses papéis se referem ao status conferido ao estudante que foi aprovado no sistema de cotas ou no sistema universal para o vestibular. O paradoxo identitário reforça a tipicidade do racismo brasileiro, que é, por exemplo, ser invisível, cordial e de resultados, pois, conforme estatísticas do Instituto Nacional de Geografia e Estatística, por exemplo, os negros compõem $70 \%$ das populações pobre e miserável do país (Carone \& Bento, 2002; Santos, 2007). O paradoxo identitário causa um transtorno psicossocial, pois paraliza a espontaneidadecriatividade do sujeito ao situá-lo no limbo do "ser" e do "não-ser" e boicota a co-criação do movimento social, pois há grupos que se unem e grupos que se desintegram em torno desse "ser". Esse mecanismo, portanto, perturba o grupo minoritário no desenvolvimento de sua capacidade de controlar os recursos escassos da sociedade. Segundo Turner (2005), o poder é a capacidade de controlar os recursos valorizados ou desejados pelos outros. O autor afirma que as bases do poder são a identidade grupal, a história, a organização social e a ideologia, mais do que a dependência e as ações relacionadas ao poder são a persuasão, a autoridade e a coerção.

No caso do Brasil, o paradoxo identitário mina ainda mais o poder dos negros, pois abrange tanto a sua consciência precária da negritude quanto a falta de consciência da "branquitude" por parte dos brancos. No confronto entre os participantes, a ideologia brasileira do paraíso racial, que banaliza a questão "quem é negro neste país?", hipnotiza opositores e favoráveis às cotas.

Estudante universalista 3: ...Mas só que, na faculdade, o povo fala: quando você vê um negro? Aí você vê uma pessoa de cabelo encoracolado e fala: Esse não é negro. Entendeu?
Estudante universalista 4: É porque geralmente o sistema de cotas nasce não do fenótipo da pessoa, mas... Não, não... eu sou negro e sei que muitas vezes na minha turma as pessoas vão falar: Ab! Fulano não é negro... Mas é porque não é pela questão do fenótipo, em si...

Estudante universalista 3: ...mas a UnB classifica por isso, praticamente.

Estudante universalista 4: Não, é auto-declaração.

Os limites de consciência racial impostos pelo paradoxo identitário contribuem para a fragilização da política afirmativa, pois não se tenta aprofundar a complexidade da identidade racial brasileira. Essa complexidade impôs aos executores da política afirmativa na UnB a concepção da banca examinadora de fotos dos candidatos ao sistema de cotas, que perdurou da implantação do sistema de cotas, no segundo semestre de 2004, até o segundo vestibular de 2007. Essa banca examinadora foi extinta porque recebeu fortes críticas (Maio \& Santos, 2005) e teve repercussão negativa na sociedade. No processo inclusivo também há grupos ou momentos de experiências em que os indivíduos ocultam a identidade, ou seja, se escondem, não se organizam e não participam de eventos relacionados à causa identitária. Este ocultamento favorece a não participação dos cotistas nos eventos relacionados à questão racial e no usofruto de apoios psicossociais e acadêmicos.

Entrevistada cotista 1: As pessoas [não participam dos eventos] porque acham que isso não vai contribuir em nada para elas, on até mesmo para a área deles. Tem gente que nem sabe onde fica o centro de convivência, que tem grupo de discussão de cotistas na internet...

Entrevistada cotista 2: Já tivemos 20 vagas para estágio e são 1.800 cotistas... Nossa! têm muitas pessoas para essas vagas! Eera para preencher todas as vagas. Mas elas ficam ociosas. As pessoas não procuram. E olha que a gente mostra pela internet, pelos e-mails. Já pregamos várias vezes cartazes, sabe? Se eles esquecem falamos de novo...

O ocultamento da identidade dos universalistas também esteve presente na fala das entrevistadas, quando expõe sobre o preconceito racial.

Entrevistada cotista 1: Realmente isso acontece na universidade: quando a gente entra num local que tem pessoas diferentes, pessoas assim, que é assim: quando não é 8 é 80, se não é de um jeito é de outro totalmente diferente, né? ... Quando tem uma pessoa preconceituosa às vezes ela se sente inibida, não é? Deve pensar: "não vou insultar, estou na universidade, as pessoas vão me condenar". Tem assim aquele sentimento e preconceito dentro de si.

Há grupos e indivíduos que vivem o processo inclusivo radicalizando a identidade, usando-a como uma "arma" pessoal ou coletiva para confrontar o grupo opositor, para demonstrar-lhe indiferença, 
isolá-lo ou para expressar desconfiança, intolerância e ódio. Nessa interação inicial da dramatização, observamos o personagem Branco Universalista, com expressão de desdém, demonstrar desconfiança do negro universalista.

Personagem Branco Universalista: E você, tirou quanto? você, 60 !

Personagem Negro Universalista: Eu? 240... E

Personagem Cotista (reage com raiva): Ué, a nota de corte é 60, estou apto para entrar na universidade! Você está dizendo que não estou apto?

Personagem Branco Universalista: Não sei dizer... tem que ver agora, se você vai conseguir acompanhar as matérias...

A identidade radical esteve presente na hostilidade entre os subgrupos, na raiva do negro, no desejo do confronto, na ênfase ao sofrimento da participante Estudante Universalista reprovada no primeiro vestibular em que se implantou o sistema de cotas, em detrimento das questões raciais. Ainda encontramos momentos em que indivíduos ou grupos tentaram flexibilizar sua identidade, para melhorar as relações no contexto inclusivo. A identidade flexibilizada está presente na cocriação, quando os indivíduos tentam desenvolver a capacidade empática e ampliar sua visão do contexto inclusivo e sociocultural. Por exemplo, nesse momento da cena dramática o personagem Negro Universalista inverte o papel e se posiciona no lugar da candidata reprovada e diz "Eu me sinto triste. Particularmente com uma frustração pessoal de mais uma vez. não ter passado. Mais uma vez. ter que voltar para casa e dizer que não passei, tenho que fazer tudo de novo. E, o pior, é saber que tem pessoas que tiveram rendimento abaixo de mim, sobre o mesmo objeto, e vão estar no curso, vão estar adiantando a vida e vão estar comemorando, pouco importando com a situação."

O Estudante Universalista, nesse momento do compartilhar, depois de viver o papel do Cotista, também demonstra o quanto a aprendizagem psicodramática lhe possibilitou flexibilizar sua identidade de universalista: O tempo todo fiquei preocupado em tentar manter um raciocinio lógico que far.parte de men personagem... Tenho que agarrar esta oportunidade, certo? Fiz. uma opção mais grata... Mas... veio a culpa, realmente. "Pô, eu passei com uma nota menor que a dela, então"... Pesou muito para o meu personagem. Imagino o que seria a vida académica de uma pessoa o tempo todo sofrendo esta culpa e, ao mesmo tempo, sofre a discriminação por ser de cota, então... Com certeza, não vou aproveitar tudo que deveria aproveitar, pois todo o tempo en serei discriminado. Corre boato de que bá professores que discriminam alunos que passam pelo PAS (Programa de Avaliação Seriada). As pessoas discriminam... Então, imagina pelo sistema de cotas... Imagino o aluno, nesta situação, deve ser muita barra.

A identidade se constitui, pois, do sentimento de pertença, dos laços afetivos entre as pessoas e das identificações que elas sentem em relação a diversas características que geram articulações políticas. Estas articulações ganham força quando pressionadas pelas identificações que têm sobrecarga de sentido ou de valor em relação às características usadas para estabelecer as diferenças nas relações intergrupais (Galinkin, 2003). Neste estudo, temos acesso a processos identitários que perturbam o sentimento de pertença dos cotistas e as articulações políticas entre os estudantes.

A aprendizagem dos novos papéis sociais de estudante cotista e de estudante universalista inclui um processo de assimilação afetiva de elementos sociais, históricos, culturais e políticos que estavam em estado caótico na sociedade. Esses elementos, ao serem reordenados com base em relações de poder (concepção, implantação e vigência de uma política afirmativa), passam a dar forma a uma nova experiência existencial. Os papéis de cotista e de universalista revigoram, pois, os jogos de poder na sociedade, sintetizam os fatos culturais e consolidam a história. Naffah Neto (1997) propõe o conceito do papel histórico, pois os papéis sociais repetem e concretizam, no âmbito microsociológico, as contradições, os conflitos e as oposições presentes nas classes sociais. Os papéis estudados são históricos porque reproduzem as relações raciais. $\mathrm{O}$ paradoxo identitário, por exemplo, instiga a idéia de que todo brasileiro deve se considerar negro (apesar da impossibilidade de viver na pele o que de fato seja ser negro), com os objetivos principais de rejeitar de imediato a política de cotas, sem se aprofundar em seu mérito ou de usá-la em benefício próprio (de preferência com muita ironia).

O temor em acirrar os conflitos raciais (Fry, 2005; Maggie, 2001) e o desejo da sociedade de proteger $\mathrm{o}$ indivíduo do constrangimento que a política focal identitária lhe provoca fazem parte do paradoxo de se evitar a exposição da identidade racial, ao mesmo tempo em que muitos apontam a perversidade do silenciamento e da anulação dessa identidade durante séculos. O Estudante Universalista é o participante que mais tenta trazer à tona essa realidade, o todo tempo no sociodrama: [Por meio da política afirmativa]... o negro vai se sentir cidadão brasileiro, participando dos espaços de poder. E essa participação ocorre, muitas vezes, aqui, dentro da universidade. Você não vai querer que o negro se identifique somente com lados mais técnicos... vamos colocar, por exemplo, jogador de futebol, 
cantores, mais ligado à arte, pessoal mais ligado à sensualidade, à voz. Não, o negro tem que ocupar o espaço acadêmico, para mover uma alteração social...

Segundo Moreno (1974), os papéis sociais são a expressão do "eu" em determinados contextos e momentos. Neste momento histórico de vigência de política afirmativa, a afetividade, as atitudes, as interações entre os sujeitos e os processos identitários detectados demonstram que os papéis de cotista e de universalista revigoram os jogos de poder na sociedade, sintetizam os fatos culturais e consolidam a história.

\section{Conclusão}

A afetividade grupal e os processos identitários podem fortalecer ou prejudicar o grupo na luta pelos bens sociais. Ao se subjugarem ao preconceito externalizado, ou silenciado, muitos estudantes cotistas se enfraquecem em sua união e organização política. Ao supervalorizar determinadas visões da política racial, muitos estudantes universalistas se unem e se fortalecem socialmente. Nessas interações afetivas observamos diversos dispositivos de poder presentes na competição social: a luta por manutenção de privilégios, a insistência em manter o discurso dominante, a dificuldade em ampliar a consciência social, o apego ao sofrimento individual em detrimento do coletivo e um mecanismo afetivo específico: a "antiempatia". Em tudo isso permeia a "apoliticidade" do estudante. Politicidade é a habilidade de saber pensar e intervir, de participar e conduzir a história (Demo, 2002). Porém, está tão enfraquecida entre os estudantes, a ponto de criarmos o termo "apoliticidade", para caracterizar, pelo menos no que se refere à inclusão racial, o desinteresse em desenvolver a consciência crítica e a participação ativa neste momento histórico, tornando-o uma oportunidade efetiva de transformação social.

Mais um dano ao processo inclusivo é a resistência dos cotistas deste estudo ao contato com as demandas psicológicas que afloram neste contexto universitário. $O$ cotista não dá importância às experiências relacionais e emocionais para o seu sucesso acadêmico e profissional e desconhece o papel da psicologia neste processo inclusivo. Todos esses fatores contribuem para o risco das cotas gerarem o efeito de poder. A política de cotas ainda corre o risco do efeito de poder quando não equilibra questões de identidade com o conflito social e quando não imprime uma ampla transformação do sistema de inserção universitária. Porém, apesar de aparentemente ter um potencial exíguo de luta social, na realidade as cotas raciais ampliam a luta de classes, ao evidenciarem as contradições culturais na sociedade, que reproduzem a desigualdade social. Em particular, a política afirmativa das cotas para negros tem o mérito de também ter a participação democrática dos movimentos sociais negros em sua concepção (Santos, 2007). Isso lhe fornece um grau de confiabilidade para ser um instrumento que contribui para a luta de classes, ampliada pelas lutas por conquistas multiculturais. O Brasil pode fazer a junção de concepção de justiça distributiva com ênfase na focalização, visando à efetiva justiça social e à redistributiva, num processo reparatório a grupos sociais que também considera a luta de classes. Assim, visualizamos que as políticas afirmativas complementam as políticas sociais e produzem novos impactos sociais, fundamentais para o incremento da luta de classes.

Apontamos a necessidade de se dar visibilidade à identidade racial e com ela promover políticas que celebrem as diferenças para que se possa efetivamente alcançar a igualdade de todos. As ações afirmativas raciais, em particular, notadamente o sistema de cotas, têm esses objetivos sociais (Gomes, 2001; Pinto, 1990; Santos \& Lobato, 2003); além de serem um recurso para o debate sobre as especificidades do capitalismo brasileiro, para a sua reconstrução mais justa, e de produzirem a identidade racial renovadora dos mecanismos de luta pelo poder (Carvalho \& Segato, 2002; Guimarães, 2002; Queiroz, 2004). As cotas para negros recebem críticas de que podem aumentar o preconceito racial (Reis, 1997). O desenvolvimento dos papéis de "cotistas" e "universalistas" reforça estes temores. Porém, a discriminação específica que surge da inclusão racial é uma decorrência dos processos identitários, silenciados há séculos o país. $\mathrm{O}$ incremento da organização política do cotista ou do estudante negro implica no fortalecimento da identidade racial. O problema não é a racialização da identidade, mas como ela é vivida. Processos identitários podem ser libertadores, desde que os jogos de poder concernentes a eles contribuam para a justiça social.

Este estudo nos faz afirmar que um projeto de inclusão racial efetiva depende de uma intervenção psicossocial multiciplinar e específica, que trabalhe com as redes sociométricas presentes na universidade, visando à flexibilização da identidade, ao diálogo empático à solidariedade entre os estudantes. É necessária uma intervenção psicossocial em que todos os seguimentos da universidade participem, com o objetivo de favorecer a diminuição da discriminação racial e de ampliar a consciência do momento histórico em que um novo papel social é gerado. A 
tarefa do psicólogo, em especial, é buscar intervenções em relação ao conflito racial que se tenta sufocar. Os conflitos sociais e raciais que emergem devem ser enfrentados; não devemos temêlos, mas torná-los uma potência geradora de novos modos relacionais libertadores da reprodução da desigualdade racial e social.

\section{Referências}

Andrews, G. R. (1997). Ação afirmativa: um modelo para o Brasil. Em J. Souza (Org.). Multiculturalismo e racismo. Uma comparação Brasil-Estados Unidos. (pp. 13-17). Brasília: Paralelo 15.

Aguiar, M. (1998). Teatro espontâneo e psicodrama. São Paulo: Ágora.

Azevedo, C. M. M. (2004). Anti-racismo e seus paradoxos: reflexões sobre cota racial, raça e racismo. São Paulo: Annablume.

Barbier, R. (2002). A pesquisa-ação (L. Didio, Trad.). Brasília: Plano (Trabalho original publicado em $\mathrm{s} / \mathrm{d})$.

Bastide, R. \& Fernandes, F. (Org.) (1955). Relações raciais entre negros e brancos em São Paulo. São Paulo: Anhembi

Carone, I. \& Bento, M. A. S. (Orgs.) (2002). Psicologia social do racismo - estudos sobre a branquitude $e$ branqueamento no Brasil. Petrópolis: Vozes.

Carvalho, J. J. \& Segato, R. L. (2002). Uma proposta de cotas para estudantes negros na Universidade de Brasília. Série Antropologia 314, Brasília: Universidade de Brasília. Obtido em 14 de dezembro de 2003 do World Wide Web: http://www.unb.br/ics/dan/serie_antro.htm.

Da Matta, R. (1997). Notas sobre o racismo à brasileira. Em A. Sant'Anna \& J. Souza (Orgs.). Multiculturalismo e racismo: uma comparação BrasilEstados Unidos (pp. 69-76). Brasília: Paralelo 15.

Demo, P. (2002). Politicidade: razão humana. Campinas: Papirus.

Demo, P. (2003a). Pobreza da pobreza. Petrópolis: Vozes.

Demo, P. (2003b). Focalização de políticas sociais um debate mais perdido do que a agenda perdida. Serviço Social e Sociedade, 76, 93-117.

Demo, P. (2007). Educação: coisa pobre para o pobre. Educação Profissional: Ciência e Tecnologia, 1(2), 165-178.
Elias, N. \& Scotson, J. (1994). The established and the outsiders. Londres: Sage.

Fry, P. (2005). A persistência da raça - ensaios antropológicos sobre o Brasil e a Africa Austral. Rio de Janeiro: Civilização Brasileira.

Galinkin, A. L. (2003). Estigma, território e organização social. Espaço e Geografia, 6(2), 149176.

Gomes, J. B. B. (2001). Ação afirmativa e princípio constitucional da igualdade - o direito como instrumento de transformação social. Rio de Janeiro: Renovar.

González Rey, F. (2005). Pesquisa qualitativa $e$ subjetividade: os processos de construção da informação (M. A. F. Silva, Trad.). São Paulo: Pioneira Thomson Learning. (Original publicado em 2005).

Guimarães, A. S. A. (1999). Racismo e anti-racismo no Brasil. São Paulo: Fundação de Apoio à Universidade de São Paulo.

Guimarães, A. S. A. (2002). Classes, raça e democracia. São Paulo: Fundação de Apoio à Universidade de São Paulo.

Kerstenetzky, C. L. (2005). Políticas Sociais: focalização ou universalização? UFF/Economia. Textos para discussão, TD 180. Obtido em 12 de julho de 2007 do World Wide Web: http://www.uff.br/econ/download/tds/UFF_T D180.pdf.

Maggie, Y. (2001). Os novos bacharéis. A experiência do movimento do pré-vestibular para negros e carentes. Novos Estudos Cebrap, 59, 193-202.

Maio, M. C. \& Santos, R. V. (2005). Política de cotas raciais, os olhos da sociedade e os usos da antropologia: o caso da UnB. Horizontes Antropológicos, 23, 32-43.

Marra, M. M. \& Costa, L. F. (2004). A pesquisa-ação e o sociodrama: uma conexão possível? Revista Brasileira de Psicodrama, 12(1), 99-116.

Minayo, M. C. S. (2006). O desafio do conbecimento: pesquisa qualitativa em saúde. São Paulo: Hucitec.

Monteiro, F. S. (2003). Retratos em branco e preto, retratos sem nenbuma cor: a experiência do disque-racismo da Secretaria de Segurança Pública do Estado do Rio de Janeiro. Dissertação de Mestrado, Universidade Federal do Rio de Janeiro: Rio de Janeiro.

Moreno, J. L. (1972). Fundamentos de la sociometria. Buenos Aires: Paidós. (s/d da publicação original). 
Moreno, J. L. (1974). Psicoterapia de grupo e psicodrama. Introdução à teoria e à práxis. (A. C. M. Cesarino Filho, Trad.). São Paulo: Mestre Jou. (Trabalho original publicado em 1959).

Moreno, J. L. (1983). Fundamentos do psicodrama (M. S. M. Neto, Trad.). São Paulo: Summus. (Trabalho original publicado em 1959).

Munanga, K. (1996). O anti-racismo no Brasil. Em: K. Munanga (Org.). Estratégias e politicas de combate à discriminação racial (pp. 79-94). São Paulo: Edusp.

Munanga, K. (1999). Rediscutindo a mestiçagem no Brasil: identidade nacional versus identidade negra. Petrópolis: Vozes.

Naffah Neto, A. (1997). Psicodrama: descolonizando o imaginário. São Paulo: Plexus.

Nery, M. P. (2003). Vinculo e afetividade. São Paulo: Ágora.

Nery, M. P., Costa L. F. \& Conceição, M. I. G. (2006). O Sociodrama como método de pesquisa qualitativa. Paidéia - Cadernos de Psicologia e Educação, 16(35), 305-314.

Perazzo, S. (1994). Ainda e sempre psicodrama. São Paulo: Ágora.

Pinto, R. P. (1990). Movimento negro e etnicidade. Estudos Afro-Asiáticos, (10), 109-124.

Popkewitz, T. S. (2001). Lutando em defesa da alma - a política do ensino e a construção do professor. Porto Alegre: Artmed.

Queiroz, D. M. (2004). Universidade e desigualdade brancos e negros no ensino superior. Brasília: Liver Livro.
Reis, F. W. (1997). Mito e valor da democracia racial. Em A. Sant'anna \& J. Souza (Orgs.). Multiculturalismo e racismo: uma comparação BrasilEstados Unidos (pp. 221-232). Brasília: Paralelo 15.

Santos, S. A. (2002). Pesquisa: ação afirmativa on utopia possivel. Brasília. ANPEd. $2^{\circ}$ Concurso Negro e Educação.

Santos, B. S. (2006). As dores do pós-neoliberalismo. Folha de São Paulo, 11 de agosto de 2006, Obtido em 22 de julho de 2007 do World Wide Web: http://www.lppuerj.net/olped/acoesafirmativas / boletim/30/artigo.htm.

Santos, S. (2007). Movimentos sociais negros, açoes afirmativas e educação. Tese de doutorado: Brasília. Santos, R. E. \& Lobato, F. (2003). Ações afirmativas - políticas públicas contra as desigualdades raciais. São Paulo: DP\&. Universidade de Brasília, Departamento de Sociologia.

Stake, E. E. (1995). The art of case study research. Newbury Park, CA: SAGE Publications.

Turner, J. C. (2005). Explaining the nature of power: a three-process theory. European Journal of Social Psychology, 35(1), 1-22.

\section{Recebido em junho de 2008 Reformulado em fevereiro de 2009 Aprovado em março de 2009}

Sobre as autoras:

Maria da Penha Nery é psicóloga, psicodramatista, doutora em Psicologia Clínica e Cultura pelo Instituto de Psicologia da Universidade de Brasília, didata-supervisora da Federação Brasileira de Psicodrama, servidora do Superior Tribunal de Justiça, presidente da Associação Brasiliense de Psicodrama (gestões 1996 e 1998), docente da Associação Brasiliense de Psicodrama e autora do livro "Vínculo e Afetividade" (2003).

Liana Fortunato Costa é psicóloga, terapeuta conjugal e familiar, psicodramatista, doutora em Psicologia Clínica pela Universidade de São Paulo, docente Permanente do Programa de Pós-graduação em Psicologia Clínica e Cultura da Universidade de Brasília e autora do livro "E quando acaba em mal me quer? Reflexões acerca do Grupo Multifamiliar e da Visita Domiciliar como instrumentos da Psicologia Clínica na comunidade" (2003). 